\title{
Association of diabetes mellitus and dementia: The Rotterdam Study
}

\author{
A. Ott ${ }^{1}$, R. P. Stolk ${ }^{1}$, A. Hofman ${ }^{1}$, F. van Harskamp ${ }^{2}$, D. E. Grobbee ${ }^{1}$, M. M. B. Breteler ${ }^{1}$ \\ ${ }^{1}$ Department of Epidemiology \& Biostatistics, Erasmus University Medical School, Rotterdam, The Netherlands \\ ${ }^{2}$ Department of Neurology, Erasmus University Medical School, Rotterdam, The Netherlands
}

\begin{abstract}
Summary Dementia and non-insulin-dependent diabetes mellitus (NIDDM) are highly prevalent disorders in the elderly. Diabetes has repeatedly been reported to affect cognition, but its relation with dementia is uncertain. We therefore studied the association between diabetes and dementia in the Rotterdam Study, a large population-based study in the elderly. Of 6330 participants, aged 55 to 99 years old, complete information on diabetes and presence of dementia was available. Diabetes was diagnosed as use of anti-diabetes medication or random or postload serum glucose over $11 \mathrm{mmol} / \mathrm{l}$. Dementia was diagnosed through a stepped approach, including a sensitive screening of all participants and a comprehensive diagnostic work-up. Diabetes was present in 724 $(11.4 \%)$ subjects. Of the 265 dementia patients 59 $(22.3 \%)$ had diabetes. Multiple logistic regression analyses, adjusting for age and sex differences, revealed a positive association between diabetes and
\end{abstract}

dementia (odds ratio: $1.3,95 \%$ confidence interval: 1.0-1.9). In particular, strong associations were found between dementia and diabetes treated with insulin (odds ratio: 3.2, 95\% confidence interval: 1.4-7.5). The relation was strongest with vascular dementia, but was also observed with Alzheimer's disease. These associations were independent of educational attainment, smoking, body mass index, atherosclerosis, blood pressure and antihypertensive drug treatment, and could not be explained by clinical cerebral infarctions. The results suggest that NIDDM is associated with dementia. Alzheimer's disease may be more frequent in elderly diabetic patients treated with insulin. [Diabetologia (1996) 39: 1392-1397]

Keywords Diabetes mellitus, insulin treatment, dementia, Alzheimer's disease, vascular dementia, aged, epidemiology.
Non-insulin-dependent diabetes mellitus (NIDDM) is a well-known risk factor for cardiovascular disease and stroke [1-3]. Apart from the obvious lesions

Received: 20 May 1996 and in revised form: 22 July 1996

Corresponding author: Dr. A. Ott, Department of Epidemiology and Biostatistics, Erasmus University Medical School, PO Box 1738, 3000 DR Rotterdam, The Netherlands

Abbreviations: AD, Alzheimer's disease; NIDDM, non-insulin-dependent diabetes mellitus; OR, odds ratio; CI, confidence interval; AGE, advanced glycation end products. caused by strokes, also subtle neurochemical, electrophysiologic and structural changes have been found in brains of patients with NIDDM [3-5]. Neuropsychologic test profiles of NIDDM patients, compared to those of healthy or hospital control subjects, showed decreased cognitive functions [6-9]. Several authors suggested that, analogous to its association with cerebral infarction, NIDDM is related to vascular dementia $[10,11]$. However, the extent to which NIDDM is associated with other dementia subtypes, in particular Alzheimer's disease (AD), is unclear [12-15].

We examined the association between NIDDM and prevalent dementia in a large population-based study. 


\section{Subjects and methods}

Subjects. The Rotterdam Study is a population-based prospective follow-up study in which several important diseases of the elderly are investigated [16]. The study focuses on four groups of diseases: neurological, cardiovascular, locomotor and ophthalmologic. All inhabitants of Ommoord, a suburb of Rotterdam, aged 55 years and older, including those living in institutions, were invited to participate in the study. Of the 10275 eligible subjects, 7983 participated in the Rotterdam Study. Between 1990 and 1993 participants were extensively interviewed at their homes and examined at the research centre in order to collect baseline data and to ascertain their health status. Dementia status was missing in 455 (6\%) subjects, mainly because they refused the cognitive screening test. Blood glucose measurements started in July 1990, after the pilot phase in which 544 randomly choosen participants were examined. Of the 7439 subjects who were examined since then, blood glucose measurements were absent in 821 (11\%), mainly due to logistic or technical problems. In the present analyses 6330 participants $(85 \%)$, with complete information on drug use, blood glucose measurements and the presence of dementia were included. Dementia and diabetes assessments took place completely independent of each other without prior knowledge of the study physicians about which associations would later be tested.

Examinations. The prevalence of dementia was assessed using a three-phase approach [17]. With a brief cognitive test, the combined Mini Mental State Examination (MMSE) [18] and Geriatric Mental State schedule (GMS-A, organic level) [19], the population was screened for dementia. This test was administered by trained research assistants. Screen positive subjects (Mini Mental State Examination score below 26 or Geriatric Mental State score above 0 ) were subsequently examined by a physician with the Cambridge Examination for Mental Disorders of the Elderly diagnostic interview [20]. Participants who were suspected of dementia after this interview underwent an extensive examination which included examinations by a neurologist, a neuropsychologist and brain magnetic resonance imaging. Based on all available information a diagnosis of dementia was then made according to Diagnostic and Statistical Manual of mental disorders criteria [21], with a subdiagnosis of AD based on National Institute of Neurological and Communicative Disorders and Stroke and Alzheimer's Disease and Related Disorders Association criteria [22] and of vascular dementia in accordance with National Institute of Neurological Disorders and Stroke and Association Internationale pour la Recherche et l'Enseignement en Neurosciences criteria [23].

Current drug use was assessed during the initial home interview. Participants were asked to show all medication they were using. Of institutionalised participants, medication was reported by the medical staff. From all participants blood was drawn by venipuncture and allowed to coagulate for $30 \mathrm{~min}$. Subjects without anti-diabetic medication subsequently received a $200 \mathrm{ml}$ glucose drink which contained $75 \mathrm{~g}$ of glucose; a second blood sample was obtained $2 \mathrm{~h}$ later. Random and post-load glucose levels were measured by the glucose hexokinase method. Diabetes was defined as the use of anti-diabetic medication or at least one glucose value greater than $11 \mathrm{mmol} / \mathrm{l}$.

Level of education was assessed during the initial interview and grouped in four levels, from primary school only, to college and higher. Smoking habits were assessed during interview and categorised as never, former or current smoking. Body mass index was calculated by dividing weight through the square of height and expressed as $\mathrm{kg} / \mathrm{m}^{2}$. Systolic blood pressure was measured with a random zero sphygmomanometer. The ankle-to-brachial index (the ratio of the systolic blood pressure measured at the ankle and the upper arm) was used as a measure of peripheral atherosclerosis: a ratio of 0.9 or below was considered positive [24]. Resting ECGs were analysed by the Modular ECG Analysis System (MEANS) computer program [25]. This program contains modules for rhythm classification, contour analyses and Minnesota coding and was shown to give very accurate ECG diagnoses [26]. The presence of coronary artery disease, was approximated by the program's diagnosis of probable or definite myocardial infarction, which was used as a second measure of atherosclerosis. A history of stroke was determined through interview or in dementia patients through informant interview, and verified with medical records.

\section{Statistical analysis}

The association between NIDDM and dementia was examined by calculating odds ratios (OR) by multivariate logistic regression with dementia as the dependent, and NIDDM, age and sex as independent variables in the model. In all regression models age was treated as a continuous variable. To assess whether this relation was different across levels of severity of NIDDM, we performed subanalyses in which we compared patients without anti-diabetes medication, patients using oral anti-diabetes medication and patients treated with insulin, to non-diabetic subjects. In addition to age and sex, we included educational level, smoking, body mass index, atherosclerosis, systolic blood pressure level and antihypertensive drug treatment to the regression model in order to adjust for confounding by these variables. To examine whether the association could be explained by an increased stroke risk in diabetic patients, the analyses were repeated in subjects without stroke history.

\section{Results}

Of the 6330 subjects in this study, 265 (4.2\%) were diagnosed with dementia (Table 1). In 194 the dementia was of the Alzheimer's disease (AD) type (73\%), 44 subjects had a vascular dementia $(17 \%)$, and 27 had other dementias $(10 \%)$. Of the AD patients $32(16 \%)$ had cerebrovascular disease, based on a history of stroke or cerebral magnetic resonance imaging findings, that was considered not directly aetiologically related to the dementia. Ages ranged from 55 to 99 years. Dementia prevalence increased sharply with age: from $0.3 \%$ in the age group 55-64 years to $30 \%$ in subjects of 85 and older. Since the older age groups had higher proportions of women, there were relatively more women with dementia. The prevalence of NIDDM also increased with age: from $6 \%$ in the age group of 55-64 years to $22 \%$ in subjects of 85 and older. NIDDM was diagnosed in $11 \%$ of the non-demented participants and in $22 \%$ of the dementia patients. Among AD, vascular and other dementia patients, 21,30 and $19 \%$ had NIDDM, respectively. Of the NIDDM patients $34 \%$ were using oral medication and $10 \%$ received insulin 
Table 1. Characteristics of the total study population, of demented and non-demented subjects

\begin{tabular}{|c|c|c|c|c|c|}
\hline & Total population & $\begin{array}{l}\text { Non-demented } \\
\text { subjects }\end{array}$ & $\begin{array}{l}\text { Demented } \\
\text { subjects }\end{array}$ & $\begin{array}{l}\text { Adjusted differ- } \\
\text { ence between } \\
\text { non-demented and } \\
\text { demented subjects }\end{array}$ & $(95 \% \mathrm{CI})$ \\
\hline Female $(\%)$ & 59.4 & 58.9 & 71.3 & & \\
\hline Age (years) & $69.3 \pm 9.1$ & $68.7 \pm 8.7$ & $83.3 \pm 7.8$ & & \\
\hline Only primary education or less (\%) & 24.2 & 22.6 & 64.8 & 20.2 & $(13.0-27.8)$ \\
\hline Ever smoking (\%) & 64.3 & 65.0 & 47.2 & -4.8 & $(-12.5-2.3)$ \\
\hline Systolic blood pressure (mm Hg) & $139.5 \pm 22.6$ & $139.4 \pm 22.5$ & $141.5 \pm 24.6$ & -7.6 & $(-10.6--4.7)$ \\
\hline Treated with antihypertensives $(\%)^{\mathrm{a}}$ & 32.5 & 32.0 & 44.9 & -4.0 & $(-9.0-1.7)$ \\
\hline Stroke history (\%) & 3.3 & 2.8 & 15.5 & 4.7 & $(2.3-8.2)$ \\
\hline
\end{tabular}

Data are mean \pm SD or percent, ${ }^{a}$ Including all beta blocker and diuretic drug use; ${ }^{\mathrm{b}}$ Adjusted for age and sex

Table 2. Association between NIDDM and dementia

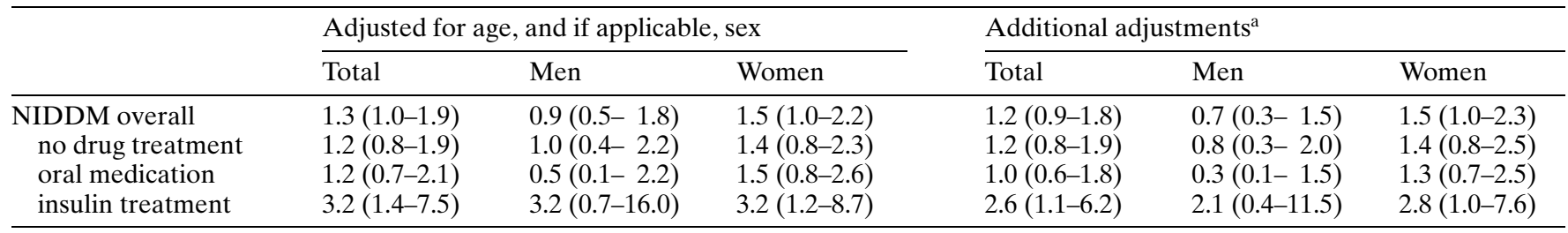

Data are odds ratio (95\% confidence interval)

a Adjusted for education, smoking, body mass index, atherosclerosis, systolic blood pressure and antihypertensive drug treatment

treatment. These proportions were similar among the dementia patients. After adjustment for age and sex differences, dementia patients had a significantly higher serum glucose level, a lower body mass index and systolic blood pressure, more frequent history of stroke and a lower educational status than subjects without dementia.

Table 2 shows the association between diabetes and dementia for the total population and for men and women separately. In women a significant association with dementia was observed (OR: 1.5, 95\% confidence interval (CI) 1.0-2.2). However, NIDDM treated with insulin was strongly correlated to dementia in both men and women (OR: $3.2,95 \% \mathrm{CI}$ : 1.4-7.5, for both sexes combined). Additional adjustments for possible confounders only marginally altered the associations.

Both NIDDM and dementia patients more often had stroke histories than participants without diabetes or dementia. Excluding subjects with a history of stroke however, did not change the association between diabetes and dementia (OR: 1.3, 95\% CI: 0.9-1.9 for overall NIDDM and OR: 3.0, 95\% CI: 1.1-7.8 for NIDDM treated with insulin).

In Table 3 the associations between diabetes and dementia subtypes are given. The association of insulin-treated NIDDM to dementia was observed for all subtypes, but was strongest for vascular dementia. Diabetes treated with oral medication was significantly associated with vascular dementia. Again additional adjustments for confounders resulted in essentially similar associations.

\section{Discussion}

In this study we investigated the relation between NIDDM and dementia. NIDDM treated with insulin was strongly associated with dementia and this was independent of level of education, smoking, body mass index, presence of atherosclerosis, systolic blood pressure and antihypertensive medication. 
Table 3. Association between NIDDM and subtypes of dementia (adjusted for age and sex)

\begin{tabular}{llllll}
\hline & \multicolumn{2}{l}{ Alzheimer's disease } & & $\begin{array}{l}\text { Vascular dementia } \\
n=44\end{array}$ & $\begin{array}{l}\text { Other dementias } \\
n=27\end{array}$ \\
\cline { 2 - 4 } & $\begin{array}{l}\text { Total } \\
n=194\end{array}$ & $\begin{array}{l}\text { Without CVD } \\
n=162\end{array}$ & $\begin{array}{l}\text { With CVD } \\
n=32\end{array}$ & & \\
\hline NIDDM overall & $1.3(0.9-1.9)$ & $1.3(0.9-2.0)$ & $1.1(0.4-2.7)$ & $2.1(1.1-4.0)$ & $1.1(0.4-2.9)$ \\
no drug treatment & $1.3(0.8-2.0)$ & $1.3(0.8-2.2)$ & $0.9(0.3-3.1)$ & $1.1(0.4-3.2)$ & $1.5(0.5-4.4)$ \\
oral medication & $1.3(0.6-2.0)$ & $0.9(0.5-2.0)$ & $1.6(0.5-5.5)$ & $3.2(1.4-7.4)$ & no cases \\
insulin treatment & $2.8(1.0-8.0)$ & $3.5(1.2-9.8)$ & no cases & $5.4(1.2-23.8)$ & $3.5(0.4-27.0)$ \\
\hline
\end{tabular}

Data are odds ratio (95\% confidence interval)

CVD, cerebrovascular disease

The association could not be explained by an increased prevalence of clinical strokes. The association was found with vascular dementia and Alzheimer's disease (AD). In vascular dementia the relation tended to be stronger with more severe NIDDM, whereas in AD an association was mainly found with NIDDM treated with insulin.

Three possible biases need to be discussed. Firstly, we did not obtain a $100 \%$ response. We do know that non-responders were on average older than the study participants. Dementia patients more often had to be excluded due to incomplete diabetes information. This, however, would only invalidate our results if the relation between NIDDM and dementia was different among non-responders as compared to participants, which we consider unlikely. Secondly, because we studied the relation between diabetes and dementia cross-sectionally, bias could have occurred due to survival effects [27]. This could have resulted in an overestimation of the relation if the relative decrease in survival due to diabetes would be greater in non-demented than demented subjects or in an underestimation if the combination of NIDDM and dementia in a patient would interact and lead to increased mortality. If anything, we consider the latter more likely. Thirdly, subtyping dementia, even if based on generally accepted diagnostic criteria, remains difficult and some misclassification cannot be excluded. Furthermore, although the criteria for vascular dementia are appropriate for identifying multiinfarct dementia, they may fail to identify subjects in whom other vascular mechanisms played an important aetiological role, and vascular factors may also be involved in $\mathrm{AD}[11,23,28,29]$. In the present study AD was associated with NIDDM, particularly when treated with insulin, even after exclusion of patients with cerebrovascular disease from the AD group.

The relation of NIDDM with dementia was similar between men and women only for NIDDM treated with insulin. In untreated and tablet-treated NIDDM a relation with dementia also seemed present in women but not in men. We do not know if this is simply due to the low number of men with both NIDDM and dementia, resulting in an unstable odds ratio with wide confidence intervals or whether this reflects a greater inpact of NIDDM on women. The latter was suggested in a report from the Framingham Heart Study, in which relatively more cardiovascular disease was found in diabetic women than men [30].

Our results indicated that atherosclerosis had only limited influence on the association between NIDDM and dementia. However, we cannot completely exclude atherosclerosis as an aetiologic factor. In order to investigate the relative contribution of strokes we investigated the association in a subgroup without history of stroke. Though the association was also found in subjects without a history of stroke it remains possible that silent infarctions due to NIDDM pathology may underlie the excess of dementia in diabetic subjects.

Our finding of an increased prevalence of vascular dementia in diabetic patients is in line with results from a study in which 175 multi-infarct dementia patients were compared with 125 age-matched neurologically normal control subjects [31]. Diabetes was 2.8 times more prevalent in cases than in control subjects. In a recent Japanese community-based study on the incidence of dementia, it was shown that NIDDM patients had an increased risk of developing vascular dementia (age adjusted relative risk: 2.8) [15]. Furthermore, Tatemichi et al. [32] showed that in stroke patients, diabetes was associated with a higher rate of dementia 3 months after the stroke (OR: 2.6).

Our findings of a relation between insulin-treated NIDDM and AD contrasts with results of studies which suggested that diabetes is less frequent among AD patients than control subjects [12-14]. These studies were relatively small, used selected clinical AD cases, and geriatric clinic patients [12], vascular dementia [13] or population control subjects [14]. Our results are in accordance with the Japanese Hisayama Study which reported that NIDDM patients had an increased risk of developing AD after 7 years of follow-up (relative risk: 2.2, 95\% CI: 1.0-4.9) [15].

The relation between NIDDM and AD may be explained by diabetic vasculopathy and its sequelae. The common coincidence of AD with cerebral infarctions and subcortical white matter lesions $[11,33,34]$ suggests that vascular factors may be important in AD. However, other and more direct mechanisms could be involved. Recently, increased glycation of 
proteins and advanced glycation end products (AGE), which may be involved in the aetiology of diabetic complications, were found in plaques and tangles of AD patients [35, 36]. AGE epitopes were even detected in the earliest states of Alzheimer brain lesions and do promote known plaque and tangle properties. Progressive glycation augments the deposition of proteins by crosslinking, it induces macrophages to secrete acute-phase reactants, thereby stimulating immune-cell response and it might contribute to nerve-cell death by the formation of free radicals [37, 38]. Alternatively, NIDDM effects on neurotransmitter metabolism could contribute to AD. In chronic diabetes, a considerable decline in the blood-brain barrier transport of choline, a precursor of acetylcholine, has been found [3]. Changes in brain glucose utilisation or insulin-induced hypoglycaemic episodes might contribute to a reduced acetylcholine synthesis [5, 39]. Blocking of acetylcholine muscarinic receptors is known to disrupt higher cognitive functions and $\mathrm{AD}$ severity is correlated to the loss of brain cholinergic activity [38, 39]. Finally, we found that the correlation between NIDDM and AD was strongest in NIDDM patients treated with insulin. Most likely these patients had a more serious and long-standing diabetes. It is however conceivable that exogenous insulin itself or hypoglycaemic episodes which frequently complicate insulin therapy [40] increase the risk of dementia and AD. A direct correlation has been reported between increased endogenous insulin level and impaired cognitive function [41].

In conclusion, we found that NIDDM, particularly when treated with insulin, is associated with dementia, both vascular dementia and AD. It is as yet unclear which pathophysiologic mechanisms could explain this association.

Acknowledgements. We gratefully acknowledge the assistance in data- collection by the staff of the Rotterdam Study centre. We also acknowledge the collaboration with the general practitioners in Ommoord. This study was made possible by financial support of the NESTOR stimulation programme for geriatric research in the Netherlands (Ministry of Health and Ministry of Education), the Netherlands Diabetes Fund, the Netherlands Organisation for Scientific Research (NWO), the Netherlands Praeventionfund and the municipality of Rotterdam.

\section{References}

1. Jarrett RJ (1989) Epidemiology and public health aspects of non-insulin-dependent diabetes mellitus. Epidemiol Rev 11: 151-171

2. Stegmayr B, Asplund K (1995) Diabetes as a risk factor for stroke. A population perspective. Diabetologia 38: 10611068

3. McCall AL (1992) The impact of diabetes on the CNS. Diabetes 41: 557-570
4. Mooradian AD (1988) Diabetic complications of the central nervous system. Endocrine Rev 9: 346-356

5. Biessels GJ, Kappelle AC, Bravenboer B, Erkelens DW, Gispen WH (1994) Cerebral function in diabetes mellitus. Diabetologia 37: 643-650

6. Perlmuter LC, Hakami MK, Hodgson-Harrington C et al. (1984) Decreased cognitive function in aging non-insulin-dependent diabetic patients. Am J Med 77: 10431048

7. Mooradian AD, Perryman K, Fitten J, Kavonian GD, Morley JE (1988) Cortical function in elderly non-insulin dependent diabetic patients. Behavioral and electrophysiologic studies. Arch Intern Med 148: 2369-2372

8. Reaven GM, Thompson LW, Nahum D, Haskins E (1990) Relationship between hyperglycemia and cognitive function in older NIDDM patients. Diabetes Care 13: 16-21

9. U'Ren RC, Riddle MC, Lezak MD, Bennington-Davis M (1990) The mental efficiency of the elderly person with type II diabetes mellitus. JAGS 38: 505-510

10. Hachinsky V (1983) Multi-infarct dementia. Neurol Clin 1: 27-36

11. Skoog I (1994) Risk factors for vascular dementia: a review. Dementia 5: 137-144

12. Wolf-Klein GP, Siverstone FA, Brod MS et al. (1988) Are Alzheimer patients healthier? JAGS 36: 219-224

13. Mortel KF, Wood S, Pavol MA, Meyer JS, Rexer JL (1993) Analysis of familial and individual risk factors among patients with ischemic vascular dementia and Alzheimer's disease. Angiology 44: 599-605

14. Landin K, Blennow K, Wallin A, Gottfries CG (1993) Low blood pressure and blood glucose levels in Alzheimer's disease. Evidence for a hypometabolic disorder? J Intern Med 233: 357-363

15. Yoshitake T, Kiyohara Y, Kato I et al. (1995) Incidence and risk factors of vascular dementia and Alzheimer's disease in a defined elderly Japanese population: the Hisayama Study. Neurology 45: 1161-1168

16. Hofman A, Grobbee DE, de Jong PTVM, van den Ouweland FA (1991) Determinants of disease and disability in the elderly. The Rotterdam Elderly Study. Eur J Epidemiol 7: 403-422

17. Ott A, Breteler MMB, Harskamp F van et al. (1995) Prevalence of Alzheimer's disease and vascular dementia: association with education. The Rotterdam study. BMJ 310: 970 973

18. Folstein MF, Folstein SE, McHugh PR (1975) "Mini-mental state". A practical method for grading the cognitive state of patients for the clinician. J Psychiat Res 12: 189 198

19. Copeland JRM, Keleher MJ, Kellet JM et al. (1976) A semi- structured clinical interview for the assessment of diagnosis and mental state in the elderly. The Geriatric Mental State Schedule. I. Development and reliability. Psychol Med 6: 439-449

20. Roth M, Huppert FA, Tym E, Mountjoy CQ (1988) CAMDEX, The Cambridge examination for mental disorders of the elderly. Cambridge University Press, Cambridge

21. American Psychiatric Association (1987) Diagnostic and statistical manual of mental disorders. 3rd edn, revised. American Psychiatric Association, Washington DC

22. McKhann G, Drachman D, Folstein M, Katzman R, Price D, Stadlan EM (1984) Clinical diagnosis of Alzheimer's disease: report of the NINCDS-ADRDA Work Group under the auspices of Department of Health and Human Services Task Force on Alzheimer's Disease. Neurology 34: 939-944 
23. Roman GC, Tatemichi TK, Erkinjuntti T et al. (1993) Vascular dementia: diagnostic criteria for research studies. Report of the NINDS-AIREN International Workshop. Neurology 43: 250-260

24. Orchard TJ, Strandness DE (1993) Assessment of peripheral vascular disease in diabetes. Diabetes care 16: 11091209

25. Kors JA, van Herpen G, Willems JL, van Bemmel JH (1992) Improvement of automated electrocardiographic diagnosis by combination of computer interpretations of the electrocardiogram and vectorcardiogram. Am J Cardiol 70: 96-99

26. Willems JL, Abreu-Lima C, Arnaud P et al. (1991) The diagnostic performance of computer programs for the interpretation of electrocardiograms. N Engl J Med 325: 1767-1773

27. Ellenberg JH (1994) Differential Postmorbidity mortality in observational studies of risk factors for neurologic disorders. Neuroepidemiology 13: 187-194

28. Breteler MMB, Ott A, Bots ML, Grobbee DE, Hofman A (1994) Atherosclerosis and dementia. J Neurol 241[Suppl 1]:26 (Abstract)

29. Skoog I, Lernfelt B, Landahl S et al. (1996) 15-Year longitudinal study of blood pressure and dementia. Lancet 347 : $1141-1145$

30. Singer DE, Nathan DM, Anderson KM, Wilson PW, Evans JC (1992) Association of $\mathrm{HbA}_{1 \mathrm{c}}$ with prevalent cardiovascular disease in the original cohort of the Framingham Heart Study. Diabetes 41: 202-208

31. Meyer JS, McClintic KL, Rogers RL, Sims P, Mortel KF (1988) Aetiological considerations and risk factors for multi-infarct dementia. J Neurol Neurosur Ps 51: 1489-1497
32. Tatemichi TK, Desmond DW, Paik M et al. (1993) Clinical determinants of dementia related to stroke. Ann Neurol 33: 568-575

33. Brun A (1994) Pathology and pathophysiology of cerebrovascular dementia: pure subgroups of obstructive and hypoperfusive aetiology. Dementia 5: 145-147

34. De la Monte SM (1989) Quantitation of cerebral atrophy in preclinical and end-stage Alzheimer's disease. Ann Neurol 25: 450-459

35. Smith MA, Sayre LM, Perry G (1996) Diabetes mellitus and Alzheimer's disease: glycation as a biochemical link. Diabetologia 39: 247 (Letter)

36. Smith MA, Sayre LM, Vitek MP, Monnier VM, Perry G (1995) Early AGEing and Alzheimer's. Nature 374: 316 (Letter)

37. Brownlee M, Vlassara H, Cerami A (1984) Nonenzymatic glycosylation and the pathogenesis of diabetic complications. Ann Intern Med 101: 527-537

38. Coyle JT, Price DL, DeLong MR (1983) Alzheimer's disease: a disorder of cortical cholinergic innervation. Science 219: 1184-1190

39. Meier-Ruge W, Bertoni-Freddari C, Iwangoff P (1994) Changes in brain glucose metabolism as a key to the pathogenesis of Alzheimer's disease. Gerontology 40: 246-252

40. Langan SJ, Deary IJ, Hepburn DA, Frier BM (1991) Cumulative cognitive impairment following recurrent severe hypoglycaemia in adult patients with insulin-treated diabetes mellitus. Diabetologia 34: 337-344

41. Kalmijn S, Feskens EJM, Launer LJ, Stijnen T, Kromhout D (1995) Glucose intolerance, hyperinsulinaemia and cognitive funtion in a general population of elderly men. Diabetologia 38: 1096-1102 